Article

\title{
Small-Scale Plastic Deformation of Nanocrystalline High Entropy Alloy
}

\author{
Sanghita Mridha ${ }^{1}$, Mageshwari Komarasamy ${ }^{1}$, Sanjit Bhowmick ${ }^{2}$, Rajiv S. Mishra ${ }^{1}$ and \\ Sundeep Mukherjee ${ }^{1, * \mathbb{D}}$
}

1 Department of Materials Science and Engineering, University of North Texas, Denton, TX 76203, USA; sanghita.mridha@gmail.com (S.M.); Mageshwari.Komarasamy@unt.edu (M.K.);

Rajiv.Mishra@unt.edu (R.S.M.)

2 Bruker Nano Surfaces, Minneapolis, MN 55344, USA; Sanjit.Bhowmick@bruker.com

* Correspondence: sundeep.mukherjee@unt.edu; Tel.: +1-940-565-4170

Received: 22 October 2018; Accepted: 16 November 2018; Published: 20 November 2018

\begin{abstract}
High entropy alloys (HEAs) have attracted widespread interest due to their unique properties at many different length-scales. Here, we report the fabrication of nanocrystalline (NC) $\mathrm{Al}_{0.1} \mathrm{CoCrFeNi}$ high entropy alloy and subsequent small-scale plastic deformation behavior via nano-pillar compression tests. Exceptional strength was realized for the NC HEA compared to pure $\mathrm{Ni}$ of similar grain sizes. Grain boundary mediated deformation mechanisms led to high strain rate sensitivity of flow stress in the nanocrystalline HEA.
\end{abstract}

Keywords: nanocrystalline materials; high entropy alloy; sputtering; deformation and fracture; strain rate sensitivity

\section{Introduction}

High entropy alloys (HEAs) represent an alloy design paradigm of combining five or more elements in equiatomic or near-equiatomic proportions [1,2]. In certain compositions, high configurational entropy suppresses intermetallic compound formation and leads to single-phase solid solution [3]. HEAs have attracted widespread interest due to their intriguing physical and mechanical properties [3]. Some of the appealing properties include exceptional ductility [3], outstanding thermal stability [4], and cryogenic fracture toughness [5]. Bulk of the research on HEAs have focused on alloy development [3], phase stability [6], and mechanical behavior of coarse grained (CG) and fine-grained systems $[3,7,8]$. But there are limited reports on nanocrystalline (NC) HEAs and their small-scale deformation behavior [9,10]. NC metals typically show very high strength [11] and good fatigue resistance [12]. Body-centered cubic NbMoTaW refractory NC HEA exhibited exceptional strength at small scales and ductility [9]. Furthermore, NC HEA retained yield strength (YS) of over 5 GPa up to $600{ }^{\circ} \mathrm{C}$ denoting an exceptional nano-structural stability [10]. Similar studies for face-centered cubic (FCC) systems could provide insights into their deformation mechanisms at reduced length-scale and pave the way for new application domains towards low-cost, durable, ductile, and strong FCC HEAs.

$\mathrm{Al}_{0.1} \mathrm{CoCrFeNi} \mathrm{HEA}$ is a canonical example of a FCC single phase multi-principal element alloy whose mechanical properties have been widely reported. Komarasamy et al. [13] examined the work hardening mechanisms in coarse-grained (CG) (a few mm) and fine-grained (FG) $(\sim 3-14 \mu \mathrm{m})$ $\mathrm{Al}_{0.1} \mathrm{CoCrFeNi} \mathrm{HEA}$ and concluded that both the conditions exhibited deformation twinning mediated plasticity. Following that, Choudhuri et al. [14] investigated the plastic deformation mechanisms of the same alloy in CG and FG conditions using transmission electron microscopy. After quasi-static tensile testing, both the microstructures exhibited nanoscale $(\sim 2 \mathrm{~nm})$ twins signifying twinning assisted plastic deformation. Wu et al. [15] also noted a similar behavior with deformation twins in both CG and FG 
materials. Furthermore, an increase in average twin spacing and a reduction in twin thickness was observed in FG condition as compared with CG material. Kumar et al. [16] examined the high strain rate compression behavior of $\mathrm{CG} \mathrm{Al}_{0.1} \mathrm{CoCrFeNi}$ HEA and observed a similar work hardening behavior as quasi-static compression. Yu et al. [17] investigated the deformation mechanism in $\mathrm{Al}_{0.1} \mathrm{CoCrFeNi}$ HEA subjected to high pressure torsion (HPT). Deformation via dislocation slip was noted at low strains while deformation twinning was activated at large plastic strains. Furthermore, a large strain rate sensitivity of 0.035 was obtained signaling grain boundary related deformation mechanism in the HPT condition. In $\mathrm{Al}_{0.1} \mathrm{CoCrFeNi} \mathrm{HEA}$, Feng et al. [18] introduced high density of nano-twins and stacking faults, and investigated the mechanical behavior at small length scales. The pillars exhibited a compressive strength of $4.0 \mathrm{GPa}$ with $15 \%$ compressive ductility. The exceptional mechanical properties were attributed to the stability of stacking faults and its effective hindrance to dislocation motion.

In this paper, we report on the nano-mechanical behavior of $\mathrm{NC}_{0.1} \mathrm{CoCrFeNi} H E A$ (average grain size $\sim 40 \mathrm{~nm}$ ) synthesized using magnetron sputtering technique. Stress-strain response was obtained by nano-pillar compression, concurrent with direct observation of their deformation behavior inside a scanning electron microscope (SEM). Different strain rates were used for strain rate sensitivity ( $m$ ) analysis.

\section{Materials and Methods}

Target alloy of composition $\mathrm{Al}_{0.1} \mathrm{CoCrFeNi}$ was prepared using high purity elements $(99.99 \%)$ and arc melted in an Ar atmosphere. A thin film of the alloy was deposited by magnetron sputtering technique (AJA International, Scituate, MA, USA) on a silicon substrate at room temperature (RT), with the base and process pressure maintained at $\sim 3 \times 10^{-6}$ torr, and $\sim 5 \times 10^{-3}$ torr, respectively. An Ar atmosphere (flow rate $10 \mathrm{sccm}$ ) was used and applied power was $75 \mathrm{~W}$. Nano-pillars were synthesized by milling the thin film using Focused Ion Beam (FIB) (FEI). A concentric circular pattern was used to mill out the nano-pillar. Gallium ion beam with current of $10 \mathrm{pA}$, and operating voltage of $30 \mathrm{kV}$ was used for milling and the pillars had an average diameter of $\sim 450 \mathrm{~nm}$. Image software was used to determine the grain size. In situ compression tests were performed on the nano-pillars with a SEM equipped with PicoIndenter PI 85 (Bruker Nano Surfaces, Minneapolis, MN, USA) using a $2 \mu \mathrm{m}$ diameter diamond flat punch. Uniaxial compression tests were conducted at strain rates of $1.2 \times 10^{-1}, 1.9 \times 10^{-2}$, and $7.5 \times 10^{-3} \mathrm{~s}^{-1}$.

\section{Results and Discussion}

Figure $1 \mathrm{a}, \mathrm{b}$ shows the $\mathrm{X}$-ray diffraction $(\mathrm{XRD})$ patterns for $\mathrm{Al}_{0.1} \mathrm{CoCrFeNi} \mathrm{HEA}$ thin film and target, respectively, demonstrating a single phase FCC structure. SEM image of the thin film (Figure 1c) shows uniformly distributed nano-sized grains with an average grain size of $\sim 40 \pm 5 \mathrm{~nm}$. SEM images of NC nano-pillar HEA before and after compression tests are shown in Figure 2. The pillar diameter was around $450 \mathrm{~nm}$ (Figure 2a). Figure $2 \mathrm{~b}$ shows the nano-pillar with the diamond flat punch just before the compression test. Uniform plastic deformation of the nano-pillar with no evidence of buckling was observed (Figure 2c). Furthermore, crack propagation parallel to the loading direction can be observed in Figure 2c. 

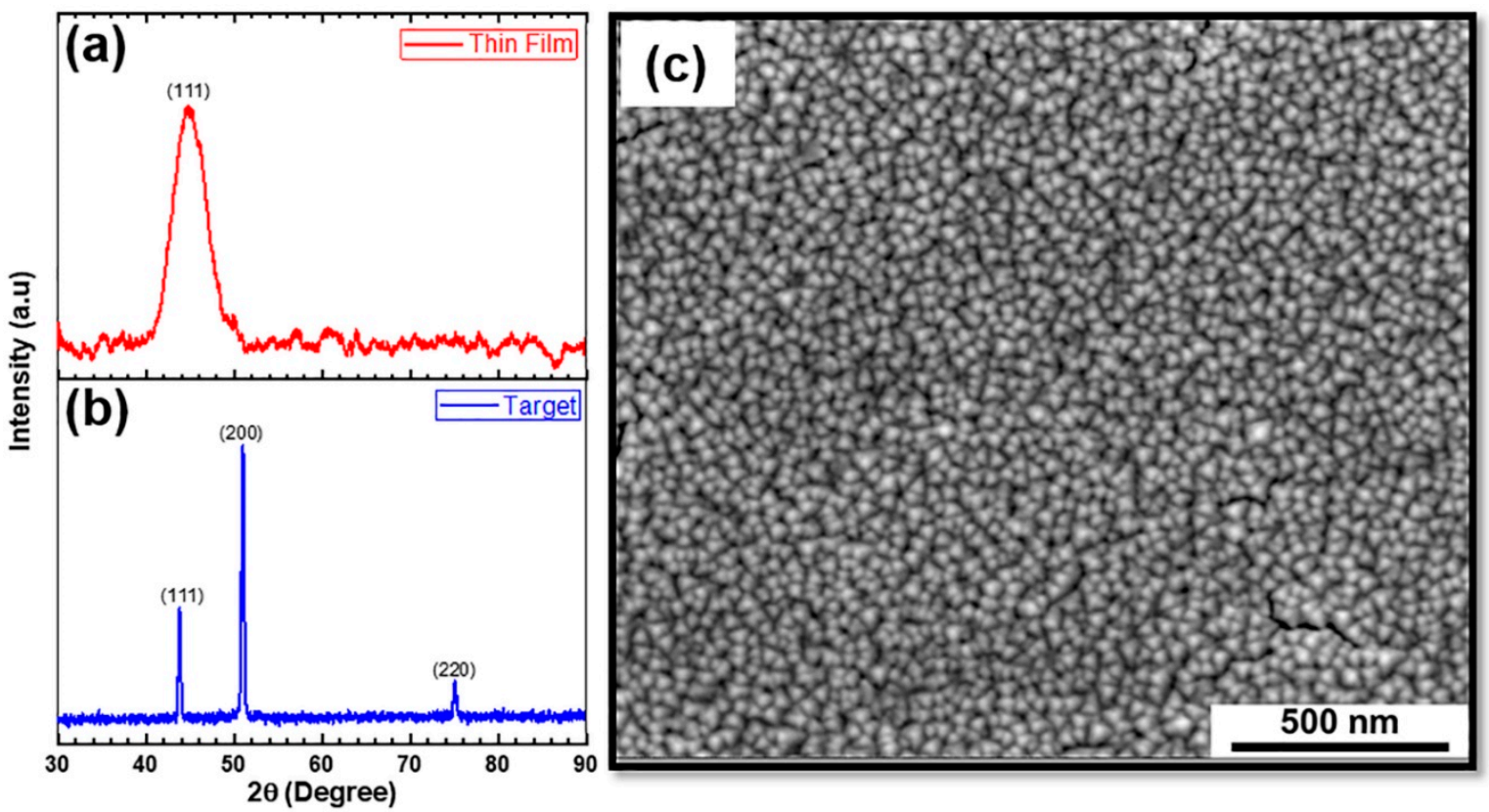

Figure 1. X-Ray diffraction (XRD) patterns of (a) $\mathrm{Al}_{0.1} \mathrm{CoCrFeNi}$ thin film and (b) $\mathrm{Al}_{0.1} \mathrm{CoCrFeNi}$ target, showing peaks corresponding to the face-centered cubic (FCC) phase; (c) high-magnification scanning electron microscope (SEM) image of the thin film showing nano-sized grains with an average grain size of $\sim 40 \pm 5 \mathrm{~nm}$.
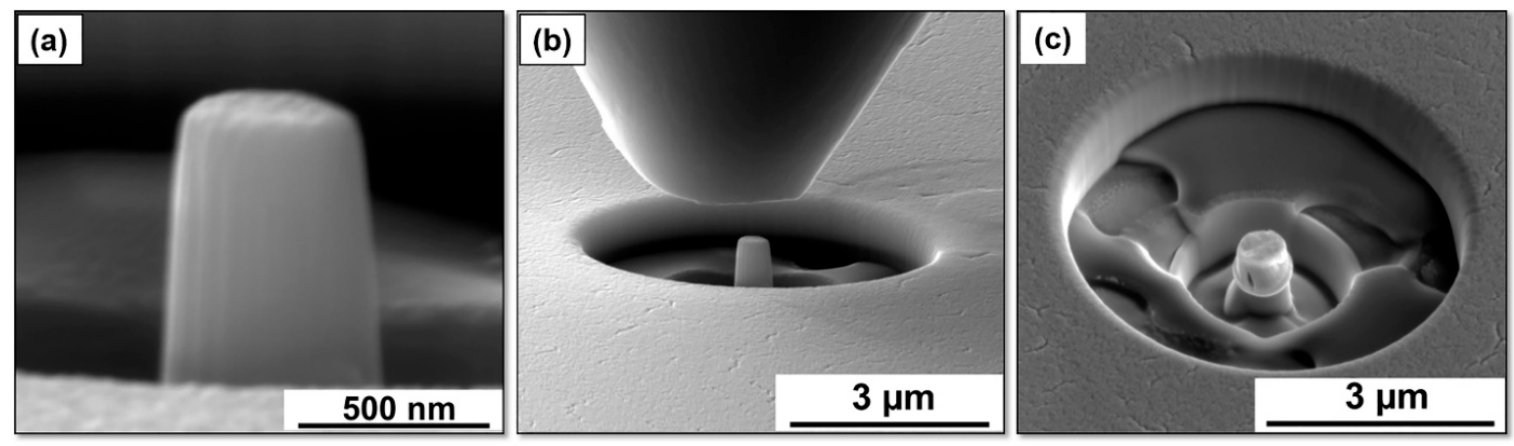

Figure 2. SEM images of the (a) nano-pillar with diameter $450 \mathrm{~nm}$ (b) diamond punch and the nano-pillar, and (c) nano-pillar after the compression test.

Compressive engineering stress-strain curve at a strain rate of $7.5 \times 10^{-3} \mathrm{~s}^{-1}$ is shown in Figure 3 a. Inset images of the pillar at various deformation intervals clearly show that the plastic deformation was uniform without buckling of the nano-pillar. YS of nano-pillar $\mathrm{Al}_{0.1} \mathrm{CoCrFeNi} \mathrm{HEA}$ at $7.5 \times 10^{-3} \mathrm{~s}^{-1}$ strain rate was $\sim 3829 \mathrm{MPa}$. YS of the CG material of the same composition was $190 \mathrm{MPa}$ indicating a 20 fold increase in strength for the NC HEA. $\mathrm{Al}_{0.1} \mathrm{CoCrFeNi}$ forms a single phase alloy with FCC crystal structure without any secondary phases. Therefore, only grain size strengthening contribution was investigated. To that end, YS versus $d^{-1 / 2}$ correlation (where $d$ represents grain size) for various HEAs, pure Ni, and the current study are shown in Figure 3b. Hall-Petch relation for various HEAs and $\mathrm{Ni}$ are shown in Figure $3 \mathrm{~b}$, based on the following equation:

$$
\sigma_{Y S}=\sigma_{\mathrm{o}}+k d^{-1 / 2}
$$

where, $\sigma_{\mathrm{o}}$ is the strength of the material for infinitely large grain size also called lattice friction stress, $k$ is the Hall-Petch coefficient, and $d$ is the grain size. The Hall-Petch equation with coefficients, $\sigma_{\mathrm{o}}$ and $k$, for all the conditions are given in the bottom inset of Figure 3b. Hall-Petch coefficients based on two independent HEA investigations were used to calculate the expected grain size strengthening 
contribution for the current condition with $\sim 50 \mathrm{~nm}$ grain size. The calculated YS based on Otto et al.'s [19] and Nilesh et al.'s [8] Hall-Petch coefficients were 2255 and $1849 \mathrm{MPa}$, respectively. Remarkably, the obtained YS in the current investigation was $\sim 1500 \mathrm{MPa}$ higher than the predicted strength values. This may be attributed to the shift in deformation mode from dislocation-controlled to grain boundary mediated plastic deformation. For the same grain size, HEAs exhibited strength values two fold higher than that of pure Ni [20]. In addition to Hall-Petch and grain boundary mediated deformation mechanism, size effect may also dominate the $\mathrm{YS}$ of $\mathrm{NC}^{\mathrm{A}} \mathrm{l}_{0.1} \mathrm{CoCrFeNi} \mathrm{HEA}$, which is out of the scope of the current paper. In CoCrCuFeNi HEA, Zhang et al. [21] investigated size-dependent YS based on micro-/nano-pillar uniaxial compression tests and noted that the HEA did exhibit size-dependent mechanical properties.
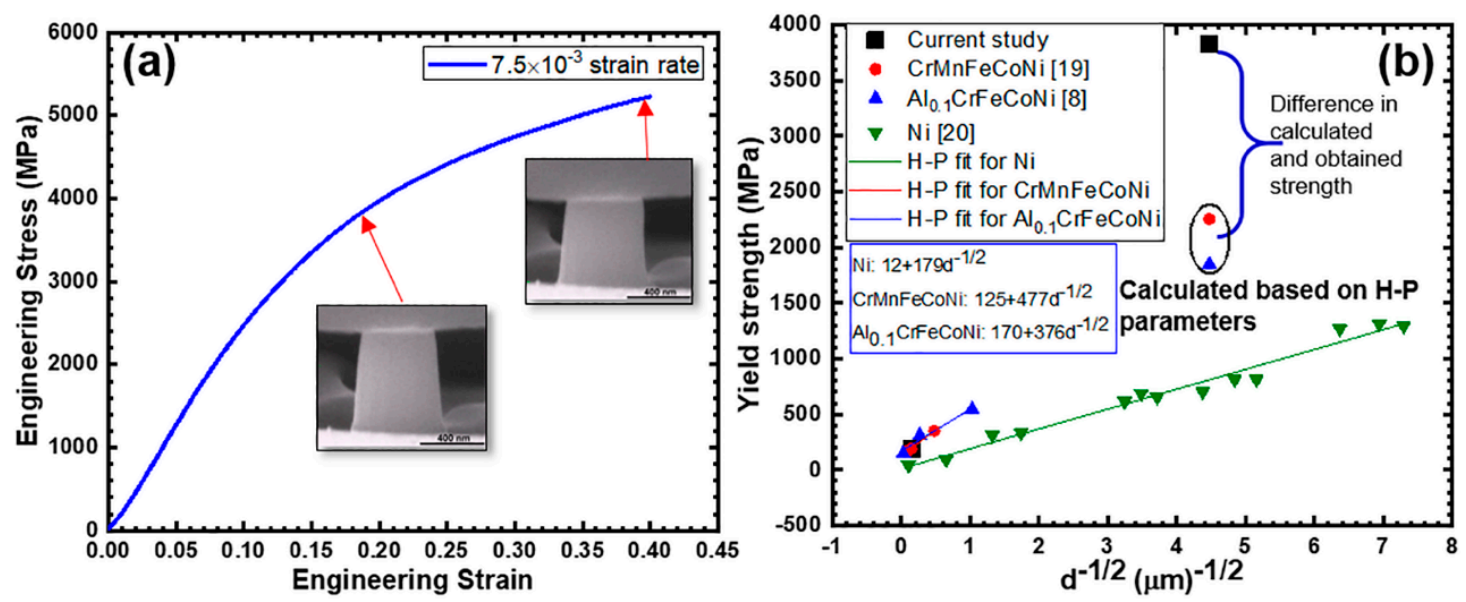

Figure 3. (a) Compressive engineering stress-strain curve at strain rate of $7.5 \times 10^{-3} \mathrm{~s}^{-1}$ showing YS of $3829 \mathrm{MPa}$. Insets show the in situ image of pillar at various stages; (b) YS vs. $d^{-1 / 2}$ plot with Hall-Petch equation fit for $\mathrm{Ni}$ and various HEAs.

Effect of strain rate on yield strength and strain rate sensitivity calculation are shown in Figure 4a,b, respectively. Stress-strain curves for $1.9 \times 10^{-2} \mathrm{~s}^{-1}$ and $1.2 \times 10^{-1} \mathrm{~s}^{-1}$ strain rates were shifted along the strain axis for a clear representation. With the increase in strain rate, yield strength of the NC nano-pillar $\mathrm{Al}_{0.1} \mathrm{CoCrFeNi} \mathrm{HEA}$ increased. This indicates a positive strain rate sensitivity of flow stress at room temperature which was observed in other investigations as well [22]. Strain rate sensitivity $(m)$ is defined as:

$$
m=\frac{\partial \ln \sigma}{\partial \ln \varepsilon}
$$

where, $\sigma$ is the flow stress and $\varepsilon$ is the strain rate. Following this equation, slope of $1 \%$ flow stress and strain rate in logarithmic scale yielded a strain rate sensitivity of 0.08 as presented in Figure $4 \mathrm{~b}$. Comparison with $m$ values reported in literature for other materials is given as inset in Figure $4 \mathrm{~b}$. As can be clearly seen, $m$ value increases with the reduction in grain size. For example, CG and NC copper exhibited $m$ values of 0.009 and 0.06 , respectively [11]. Furthermore, $m$ value of CG HEA was higher than CG conventional metals/alloys, which was attributed to fluctuating lattice energy controlled deformation mechanism. In the current investigation, due to the nano-scale grain size, there is high possibility that dislocation controlled processes were suppressed and grain-boundary mediated processes were activated. Furthermore, $m$ value of 0.08 for NC HEA would translate into lower apparent activation volume of dislocation as compared to NC copper with $m$ value of 0.06 . Therefore, in addition to differences in CG material due to lattice distortion controlled dislocation activity, current results suggest that grain boundary mediated plastic deformation was influenced by the inherent lattice distortion of HEA. 

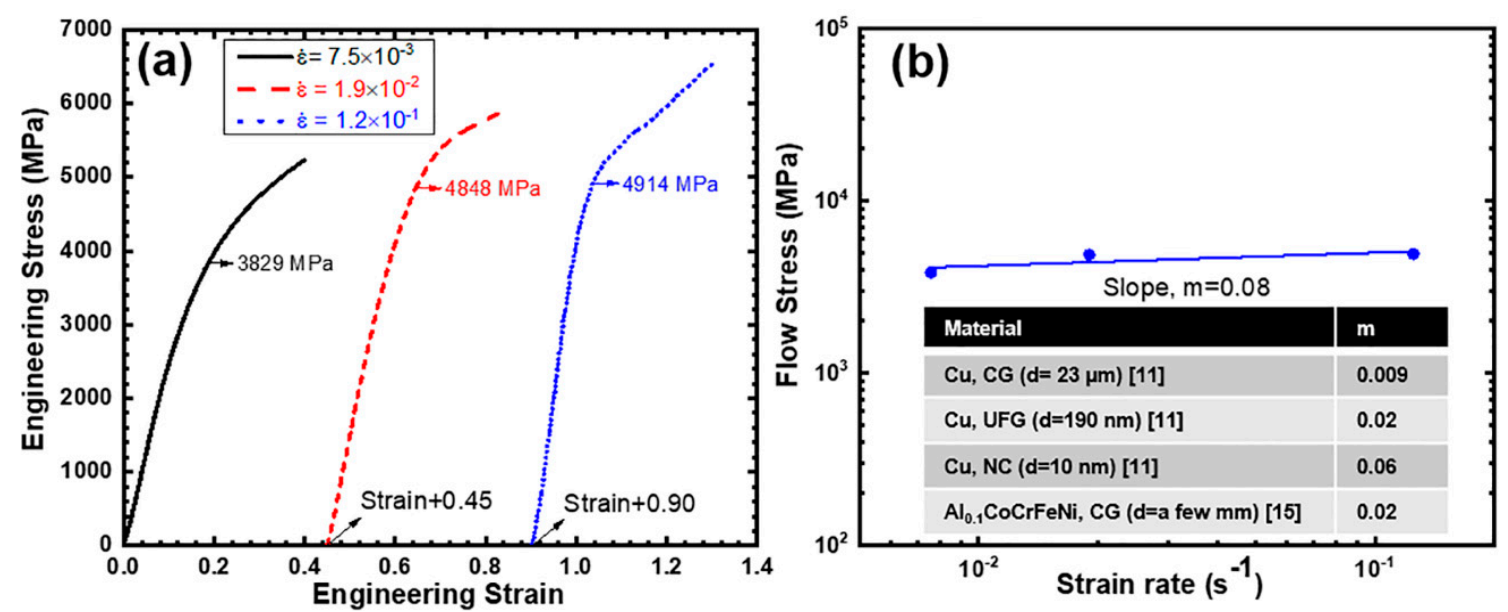

Figure 4. (a) Compressive engineering stress-strain plot at different strain rates showing the increase in tensile strength with increase in strain rate; (b) flow stress at $1 \%$ offset strain versus strain rate plot in logarithmic scale to calculate strain rate sensitivity $(m)$.

An important implication of the current investigation is the viability of nano-crystalline HEAs for use in high-strength applications without expensive refractory elements such as $\mathrm{Mo}, \mathrm{Ta}, \mathrm{W}$, and $\mathrm{Nb}$. In fact, body centered cubic NbMoTaW HEA pillar of $1 \mu \mathrm{m}$ diameter exhibited yield strength similar to the current $\mathrm{Al}_{0.1} \mathrm{CoCrFeNi}$ face centered cubic nano-pillar [9]. Therefore, the current nanostructured alloy is a cost-effective alternative towards achieving ultra-strong and ductile wires for small-scale applications.

\section{Conclusions}

In conclusion, exceptional strength was seen for nano-crystalline $\mathrm{Al}_{0.1} \mathrm{CoCrFeNi} \mathrm{HEA}$ similar to refractory HEAs of comparable length scales. This was attributed to grain boundary mediated plastic deformation processes. The strain rate sensitivity was higher than conventional NC material implying an even lower activation volume of dislocations.

Author Contributions: Conceptualization, S.M.; Formal analysis, S.B. and R.S.M.; Investigation, S.M. and M.K.; Supervision, S.M.; Writing-original draft, S.M., M.K. and S.M.

Funding: This research received no external funding.

Conflicts of Interest: The authors declare no conflict of interest.

\section{References}

1. Yeh, J.W.; Chen, S.K.; Lin, S.J.; Gan, J.Y.; Chin, T.S.; Shun, T.T.; Tsau, C.H.; Chang, S.Y. Nanostructured high-entropy alloys with multiple principal elements: Novel alloy design concepts and outcomes. Adv. Eng. Mater. 2004, 6, 299-303. [CrossRef]

2. Cantor, B.; Chang, I.T.H.; Knight, P.; Vincent, A.J.B. Microstructural development in equiatomic multicomponent alloys. Mater. Sci. Eng. A. 2004, 375-377, 213-218. [CrossRef]

3. Miracle, D.B.; Senkov, O.N. A critical review of high entropy alloys and related concepts. Acta Mater. 2017, 122, 448-511. [CrossRef]

4. Dolique, V.; Thomann, A.L.; Brault, P.; Tessier, Y.; Gillon, P. Thermal stability of AlCoCrCuFeNi high entropy alloy thin films studied by in-situ XRD analysis. Surf. Coat. Technol. 2010, 204, 1989-1992. [CrossRef]

5. Gludovatz, B.; Hohenwarter, A.; Catoor, D.; Chang, E.H.; George, E.P.; Ritchie, R.O. A fracture-resistant high-entropy alloy for cryogenic applications. Science 2014, 345, 1153-1158. [CrossRef] [PubMed]

6. Otto, F.; Yang, Y.; Bei, H.; George, E.P. Relative effects of enthalpy and entropy on the phase stability of equiatomic high-entropy alloys. Acta Mater. 2013, 61, 2628-2638. [CrossRef]

7. Zhang, Y.; Zuo, T.T.; Tang, Z.; Gao, M.C.; Dahmen, K.A.; Liaw, P.K.; Lu, Z.P. Microstructures and properties of high-entropy alloys. Prog. Mater. Sci. 2014, 61,1-93. [CrossRef] 
8. Kumar, N.; Komarasamy, M.; Nelaturu, P.; Tang, Z.; Liaw, P.K.; Mishra, R.S. Friction stir processing of a high entropy alloy $\mathrm{Al}_{0.1} \mathrm{CoCrFeNi}$. JOM 2015, 67, 1007-1013. [CrossRef]

9. Zou, Y.; Ma, H.; Spolenak, R. Ultrastrong ductile and stable high-entropy alloys at small scales. Nat. Commun. 2015, 6, 1-8. [CrossRef] [PubMed]

10. Zou, Y.; Wheeler, J.M.; Ma, H.; Okle, P.; Spolenak, R. Nanocrystalline High-Entropy Alloys: A New Paradigm in High-Temperature Strength and Stability. Nano Lett. 2017, 17, 1569-1574. [CrossRef] [PubMed]

11. Chen, J.; Lu, L.; Lu, K. Hardness and strain rate sensitivity of nanocrystalline Cu. Scr. Mater. 2006, 54, 1913-1918. [CrossRef]

12. Padilla, H.A.; Boyce, B.L. A Review of fatigue behavior in nanocrystalline metals. Exp. Mech. 2010, 50, 5-23. [CrossRef]

13. Komarasamy, M.; Kumar, N.; Tang, Z.; Mishra, R.S.; Liaw, P.K. Effect of microstructure on the deformation mechanism of friction stir-processed $\mathrm{Al}_{0.1} \mathrm{CoCrFeNi}$ high entropy alloy. Mater. Res. Lett. 2015, 3, 30-34. [CrossRef]

14. Choudhuri, D.; Komarasamy, M.; Ageh, V.; Mishra, R.S. Investigation of plastic deformation modes in $\mathrm{Al}_{0.1} \mathrm{CoCrFeNi}$ high entropy alloy. Mater. Chem. Phys. 2018, 217, 308-314. [CrossRef]

15. Wu, S.W.; Wang, G.; Yi, J.; Jia, Y.D.; Hussain, I.; Zhai, Q.J.; Liaw, P.K. Strong grain-size effect on deformation twinning of an $\mathrm{Al}_{0.1} \mathrm{CoCrFeNi}$ high-entropy alloy. Mater. Res. Lett. 2017, 5, 276-283. [CrossRef]

16. Kumar, N.; Ying, Q.; Nie, X.; Mishra, R.S.; Tang, Z.; Liaw, P.K.; Brennan, R.E.; Doherty, K.J.; Cho, K.C. High strain-rate compressive deformation behavior of the $\mathrm{Al}_{0.1} \mathrm{CrFeCoNi}$ high entropy alloy. Mater. Des. 2015, 86, 598-602. [CrossRef]

17. Yu, P.F.; Cheng, H.; Zhang, L.J.; Zhang, H.; Jing, Q.; Ma, M.Z.; Liaw, P.K.; Li, G.; Liu, R.P. Effects of high pressure torsionon microstructures and properties of an $\mathrm{Al}_{0.1} \mathrm{CoCrFeNi}$ high-entropy alloy. Mater. Sci. Eng. 2016, 655, 283-291. [CrossRef]

18. Feng, X.; Zhang, J.; Wu, K.; Liang, X.; Liu, G.; Sun, J. Ultrastrong Al0.1CoCrFeNi high-entropy alloys at small scales: effects of stacking faults vs. nanotwins. Nanoscale 2018, 10, 13329-13334. [CrossRef] [PubMed]

19. Otto, F.; Dlouhý, A.; Somsen, C.; Bei, H.; Eggeler, G.; George, E.P. The influences of temperature and microstructure on the tensile properties of a CoCrFeMnNi high-entropy alloy. Acta Mater. 2013, 61, 5743-5755. [CrossRef]

20. Xiao, C.; Mirshams, R.A.; Whang, S.H.; Yin, W.M. Tensile behavior and fracture in nickel and carbon doped nanocrystalline nickel. Mater. Sci. Eng. A. 2001, 301, 35-43. [CrossRef]

21. Zhang, H.; Siu, K.W.; Liao, W.; Wang, Q.; Yang, Y.; Lu, Y. In situ mechanical characterization of CoCrCuFeNi high-entropy alloy micro/nano-pillars for their size-dependent mechanical behavior. Mater. Res. Express 2016, 3, 94002. [CrossRef]

22. Komarasamy, M.; Kumar, N.; Mishra, R.S.; Liaw, P.K. Anomalies in the deformation mechanism and kinetics of coarse-grained high entropy alloy. Mater. Sci. Eng. A 2016, 654, 256-263. [CrossRef] 